\title{
Assembly rules for New England ant assemblages
}

\author{
Nicholas J. Gotelli and Aaron M. Ellison
}

Gotelli, N. J. and Ellison, A. M. 2002. Assembly rules for New England ant assemblages. - Oikos 99: 591-599.

Community assembly rules specify patterns of species co-occurrence and morphology dictated by interspecific competition. We collected data on the occurrence of groundforaging ant species in 22 ombrotrophic bogs and adjacent forest plots of New England to test two general assembly rules: reduced co-occurrence of species among communities, and even spacing of body sizes of species within communities. We used null models to generate random communities unstructured by competition and evaluated patterns at regional and local spatial scales. At the regional scale, species co-occurrence in forests, but not bogs, was less than expected by chance, whereas, at the local scale, co-occurrence in both habitats was not different from random. At the regional scale, spacing of body size distributions was random (in bogs) or aggregated (in forests). At the local scale, body size patterns were weakly segregated in bogs, but random or weakly aggregated in forests. In bogs, size ratio constancy was accompanied by greater generic diversity than expected. Although assembly rules were originally developed for vertebrate communities, they successfully explained some patterns in New England ant assemblages. However, the patterns were contingent on spatial scale, and were distinctly different for bog and forest communities, despite their close proximity and the presence of many shared species in both assemblages. The harsh physical conditions of bogs may act as a habitat filter that alters community assembly rules.

N. J. Gotelli, Dept of Biology, Univ. of Vermont, Burlington, VT 05405, USA (ngotelli@zoo.uvm.edu). - A. M. Ellison, Dept of Biological Sci., Mount Holyoke College, South Hadley, MA 01075, USA (present address: Harvard Forest, Harvard Univ., P.O. Box 68, Petersham, MA 01366, USA).

The study of assembly rules that reflect species interactions is an active research area of community ecology (Drake 1990, Cornell 1999, Weiher and Keddy 1999). Although assembly rules might imply the study of temporal changes in community composition (Keddy and Weiher 1999), most investigators have used assembly rules as descriptions of patterns at the community level (Wilson 1999). The theoretical framework of interspecific competition leads to two basic predictions: first, among a set of communities, species should co-occur less often than expected by chance (Elton 1946, Pielou and Pielou 1968, Diamond 1975, Simberloff and Connor 1981). Second, within a community, the species that do co-occur should differ substantially in body size or morphology (Brown and Wilson 1956, Hutchinson 1959, Grant 1972), so that overlap in resource utiliza- tion is reduced (MacArthur and Levins 1967, Schoener 1974, Wiens 1982)

In this study, we used null model analysis (Gotelli and Graves 1996) to test for patterns of co-occurrence and body size overlap of continental ground-foraging ant assemblages. Ants are an ideal taxon to use for testing patterns of community assembly because they are important terrestrial omnivores (Hölldobler and Wilson 1990), and because ant community structure is widely believed to be organized by interspecific interactions (Levings and Traniello 1981, Morrison 1996, Cerdá et al. 1998). Evidence for competition in ant communities includes dominance hierarchies (Savolainen and Vepsäläinen 1989, Andersen 1992, Punttila et al. 1996), interspecific aggression (Cole 1983), competitive displacement (Porter and Savignano

Accepted 10 June 2002

Copyright (C) OIKOS 2002

ISSN 0030-1299 
1990, Holway 1998), and the existence of chemical warfare (Andersen et al. 1991). We sampled ant communities across north-central New England (regional scale) and used data collected within small sampling grids at each site to analyze species co-existence at the local scale. At both spatial scales, we used a battery of null model algorithms to test for patterns of non-random co-occurrence and body size overlap.

\section{Materials and methods}

\section{Ant sampling and body size measurements}

We censused ants in 22 high-grade, undisturbed bogs and their surrounding forests in northern New England (Vermont, Massachusetts, and Connecticut). Sites were spread across the states and spanned three degrees of latitude $\left(42-45^{\circ} \mathrm{N}\right)$ At each site, we established two $5 \times 5$ grids of 25 pitfall traps spaced $2 \mathrm{~m}$ apart $\left(64 \mathrm{~m}^{2}\right)$. One grid was located in the center of the bog, and one in the adjacent forest, $<100 \mathrm{~m}$ away. Each pitfall trap consisted of a $95 \mathrm{~mm}$ diameter plastic cup, filled with $20 \mathrm{~mm}$ of dilute soapy water. A similar trap design has proven effective in other regional surveys of ant faunas (Andersen 1997, Gotelli and Arnett 2000). Traps were buried so that the upper lip of each trap was flush with the surface of the substrate, and left in place for 48 hours during dry weather. Trap contents were fixed in the field in $95 \% \mathrm{EtOH}$. At each site, two complete ant surveys were conducted, separated by approximately 42 days. The same grids were re-sampled in the second survey. We started sampling on 2 June 1999 and finished on 29 August 1999. Pitfall trapping was supplemented with baiting, leaf-litter surveys, and hand collecting. Full details of sampling procedures are given in Gotelli and Ellison (2002).

We used Weber's length (Brown 1953), the distance from the anterodorsal margin of the pronotum to the posteroventral margin of the propodeum (Longino 1997), as a simple measure of ant body size. For every species collected within a habitat at a site, we measured the index on six randomly selected workers, or the maximum number that were collected, whichever number was smaller. Queens and morphologically aberrant individuals were not measured. We did not distinguish between major and minor workers in the genus Camponotus. We calculated a mean Weber's length for each species at a site, and then averaged these values to create a single index of body size for each species collected within a habitat. Our null model analyses did not incorporate body size variation within species (Losos 1990), which was small compared to variation among species and genera (e.g. Camponotus vs Leptothorax).

\section{Regional and local scales of analysis}

We analyzed species co-occurrence and body size overlap at two distinct spatial scales: regional and local. At the regional scale, co-occurrence data were organized as a presence-absence matrix for each habitat. Each row of the matrix was a different species, each column was a different site $(n=22)$, and the entries were the presence or absence of a species at a site. Data from all collection methods (pitfall traps, baits, leaf-litter samples, hand collection) were combined to construct this presence-absence matrix.

At the local scale, we constructed presence-absence matrices for the pitfall grid data only. Each row of the matrix was a different species, and each column was a different pitfall trap $(\mathrm{n}=25)$ within the grid. Thus, 44 presence-absence matrices were constructed for analysis at the local scale, 22 from bogs and 22 from forests. We analyzed the early and the late-season grid data separately. A few grids could not be analyzed because fewer than two species were collected.

To analyze body size overlap at the regional scale, we used the list of all species collected from bog or forest habitats, combining data from all sites, times, and sampling methods. At the local scale, we used the list of species collected from a particular site (all trapping method and times combined) and compared body size distributions to those expected from random colonization from the regional source pool. Again, some sites could not be analyzed because at least three species are necessary to test for constancy in body size ratios.

We used simple indices to describe the pattern of co-occurrence and species body size overlap. These were compared to indices calculated for null assemblages, in which the body size or occurrence of each species was randomly assigned. We compared the observed index to the histogram of indices from 5000 randomly constructed communities (1000 for size ratio tests), and determined the exact tail probability for the observed value (Manly 1991). All null model analyses were conducted with EcoSim Version 6.0 (Gotelli and Entsminger 2001a).

\section{Co-occurrence analysis}

We used Stone and Roberts (1990) C-score as a metric to quantify the pattern of co-occurrence within a presence-absence matrix. The larger the $\mathrm{C}$-score, the less the average pairwise species co-occurrence. For an assemblage that is competitively structured, the C-score should be significantly larger than expected by chance (Gotelli 2000). We analyzed each presence-absence matrix at local and regional scales with three null models:

\section{Fixed-fixed}

In this null model, the row and column sums of the original matrix are preserved. Thus, each random com- 
munity contains the same number of species as the original community (fixed column total), and each species occurs in the same frequency as in the original community (fixed row total; Connor and Simberloff 1979). This algorithm has good statistical properties (low frequency of Type I and Type II errors) when tested against random and structured matrices (Gotelli 2000). We created the random matrices by a swapping algorithm, in which the original matrix is shuffled through repeated swapping of random submatrices (Stone and Roberts 1990, Manly 1995). Similar results were obtained with an unbiased version of Sanderson et al's. (1998) knight's tour algorithm, in which an empty matrix is filled randomly one cell at a time (Gotelli and Entsminger 2001b).

\section{Fixed-equiprobable}

In this null model, only the row sums are fixed, and the columns $(=$ sites $)$ are treated as equiprobable. Thus, each species occurrences are randomly re-shuffled within each row of the matrix. This null model treats all of the sites as equally suitable for all species (Haukisalmi and Henttonen 1998), and was applied only at the local scale of analysis.

\section{Weighted-fixed}

In this null model, the column totals are fixed, so that each site in the null community contains the same number of species as each site in the original community. However, the occurrence frequency of each species is proportional to the total abundance in pitfall traps summed across all sites within a habitat and all sampling periods. For the small number of species that did not occur in pitfall traps, we assigned an abundance weight of 1 , corresponding to a rare species that was represented by only 1 individual in a pitfall trap.

\section{Body size overlap analysis}

To test the hypothesis that body size ratios show constant spacing, we first plotted body sizes on a $\log _{10}$ scale, and then calculated the difference between adjacent species. We calculated the variance in these segment lengths $\left(\sigma_{\mathrm{sl}}^{2}\right)$ as an index of constancy in body size ratios (Poole and Rathcke 1979). If co-existing species differ from one another by a constant size ratio, then the segments would be identical in length and $\sigma_{\mathrm{sl}}^{2}=0.0$. The more heterogeneity in size ratios of adjacent species, the larger $\sigma_{\mathrm{sl}}^{2}$. A competitively structured community should contain species that generate an unusually small $\sigma_{\mathrm{sl}}^{2}$ compared to a randomly assembled community (Fig. 1). We used four null models to generate communities with random body size distributions:

\section{Uniform}

In this null model, the endpoints of the distribution are fixed by the largest and smallest species in the assemblage. The remaining $\mathrm{n}-2$ species are chosen from a random, $(\log )$ uniform distribution within these limits. This null model assumes that, in evolutionary time, any possible configuration of body sizes is equiprobable, within the limits imposed by the largest and smallest species (Simberloff and Boecklen 1981).

In our study, the uniform null model was the only one that could be applied at the regional scale of analysis. At the local scale, we used the regional list of species from each habitat as a source pool for three other null models:

\section{Equiprobable source pool}

In this null model, species are drawn randomly and equiprobably from the regional list of species compiled for the habitat. Once a species is drawn, it cannot be selected again for a particular null assemblage. In contrast to the uniform null model, this null model con-
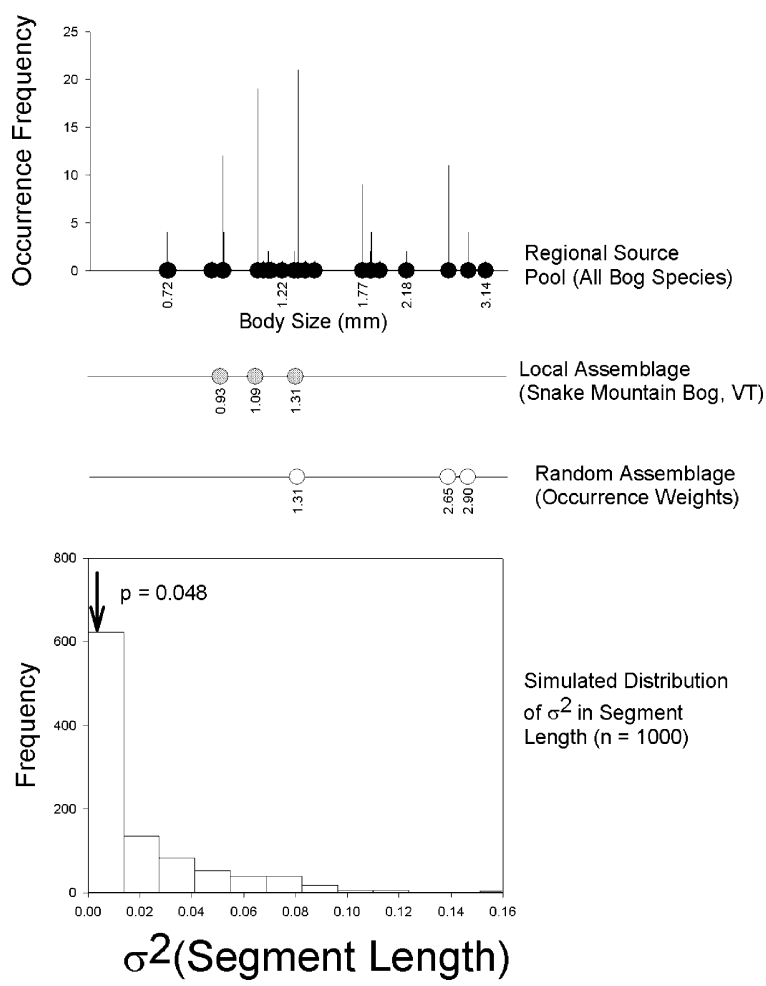

Fig. 1. Protocol for testing for even spacing of body sizes. The upper graph shows the distribution of body sizes (log10 scale) of the 24 ant species in the regional species pool for bog habitats. The vertical line is the occurrence frequency in the 22 sampled bogs. The next panel shows the sizes of the 3 species that occur locally in Snake Mountain Bog, VT, and a randomly assembled community in which three species were drawn randomly with probabilities proportional to occurrence frequencies. For the real and simulated communities, the variance in segment length of adjacent species is calculated $\left(\sigma_{\mathrm{sl}}^{2}\right)$. The observed variance for the species in Snake Mountain Bog was smaller than the variance in most of the random assemblages, indicating constant body size ratios. 
strains possible body sizes of species in the null assemblage to those represented by species in the region as a whole.

\section{Occurrence-weighted source pool}

In this null model, species are also drawn randomly from the regional species list, but the relative probability that a species is drawn is proportional to the number of sites in which it occurred.

Abundance-weighted source pool

In this null model, species are also drawn randomly from the regional species list, but the relative probability that a species is drawn is proportional to its total abundance from the pitfall trap collections within a habitat, summed across all sites and sampling periods Species that were not represented in pitfall traps were assigned an abundance of 1 for the purposes of calculating weights.

\section{Generic diversity}

We used a rarefaction analysis (Simberloff 1970, Hurlbert 1971) to test the hypothesis that generic diversity within local communities is higher than expected by chance. Because genera differ significantly from one another in body size, such a pattern of increased generic diversity might be associated with non-random spacing of body sizes. We drew species randomly and equiprobably from each regional source pool to estimate the expected number of genera represented in local communities (Gotelli and Colwell 2001). For each local community, we made 100 random draws of an equivalent number of species, and then calculated the average as the expected number of genera in a random assemblage. Within bogs and within forests, we then tabulated the number of assemblages for which the observed generic diversity was greater than expected, and assessed the distribution of values with a binomial probability test.

\section{Results}

\section{Community composition}

In total, just over 10000 individual ants were collected, 6163 of which came from pitfall traps. We identified 24 species of ants in nine genera from the bogs, and 37 species in 14 genera from surrounding forests. Species density per bog site averaged $4.9 \pm 0.63$ (se) and ranged from 2 to 14 species, whereas species density per forest site averaged $9.2 \pm 0.92$ and ranged from 4 to 18 species (matched pairs $\mathrm{t}_{21}=5.98, \mathrm{P}<0.0001$ ). The bog ant fauna was dominated by Myrmica lobifrons and Dolichoderus pustulatus, and the forest ant fauna was domi- nated by Aphaenogaster rudis (s.1.), Camponotus pennsylvanicus, and Leptothorax longispinosus. Whereas D. pustulatus is a generalist that occurs in a variety of open habitats, $M$. lobifrons is a specialist of boreal bogs and other humid microsites (A. Francoeur, pers. comm.). Twenty-two species were common to both habitats, with two species collected from only bogs and 15 species collected from only forests. Our species lists are typical for New England forests (Herbers 1989, Weseloh 1995).

\section{Co-occurrence patterns}

At the regional scale, forest ant assemblages had significantly less co-occurrence than expected by chance (large C-score), for both the fixed-fixed and weightedfixed null models (Fig. 2). In contrast, bog ant assemblages appeared either random (fixed-fixed model) or slightly aggregated (weighted-fixed model). At the local scale, there was little evidence of non-randomness of ants captured in pitfall traps. A small number of assemblages showed significant positive or negative deviations. The meta-analysis revealed no strong patterns, although the late-season forest samples tended towards significant aggregation (Table 1).

\section{Body size overlap patterns}

At the regional scale, body size overlap in bog ant assemblages appeared random with respect to a uni-

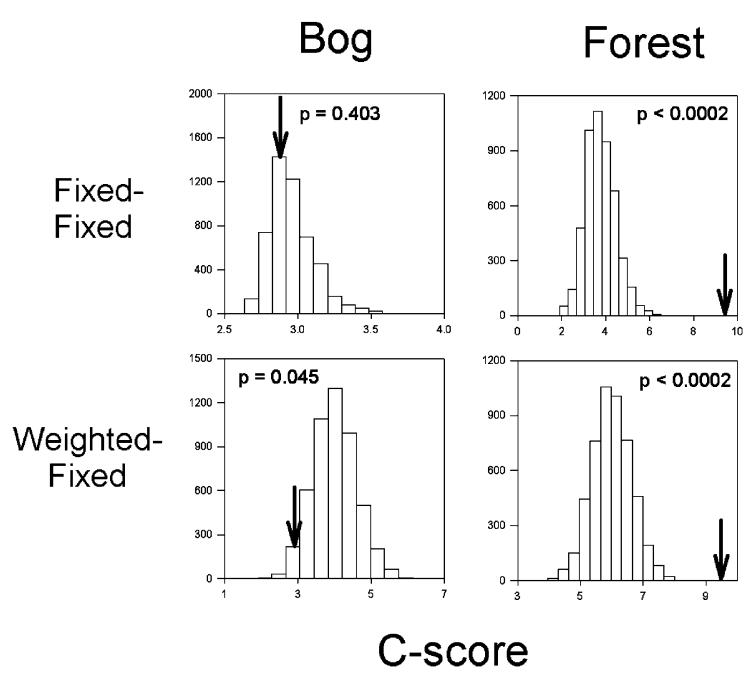

Fig. 2. Co-occurrence patterns at the regional scale of analysis. The histograms give the frequencies of simulated C-scores for bog and forest assemblages using two different null models (fixed-fixed, weighted-fixed; see text for details). Arrows indicate observed $\mathrm{C}$-scores, with associated tail probabilities. Communities structured by interspecific competition should exhibit unusually large $\mathrm{C}$-scores (less species co-occurrence). 
Table 1. Meta-analysis of effect sizes for co-occurrence patterns at the local scale. "Lower tail" and "Upper tail" indicate the number of assemblages for which the observed C-score was respectively less than or greater than predicted by the null model. The number in parentheses indicates the number of assemblages with significant patterns $(\mathrm{p}<0.05$, one-tailed test). A one-sample $\mathrm{t}$-test was used to test the hypothesis that the standardized effect size (SES) for the set of assemblages does not differ from zero. $\mathrm{SES}=\left(I_{\text {obs }}-I_{\text {sim }}\right) / s_{\text {sim }}$ where $I_{\text {sim }}$ is the mean index of the simulated communities, $s_{\text {sim }}$ is the standard deviation, and $I_{o b s}$ is the observed index. Bonferonni probabilities are corrected for all of the tests in this table. Communities with little co-occurrence should frequently reject the null hypothesis in the upper tail, and the meta-analysis pattern would be an effect size significantly greater than 0.0 .

\begin{tabular}{llrrrrrrr}
\hline Habitat & Model & $\begin{array}{l}\text { Lower } \\
\text { tail }\end{array}$ & $\begin{array}{l}\text { Upper } \\
\text { tail }\end{array}$ & $\begin{array}{l}\text { Average } \\
\text { effect } \\
\text { size }\end{array}$ & $\begin{array}{l}\text { SD of } \\
\text { effect } \\
\text { size }\end{array}$ & $\mathrm{t}$ & $\mathrm{p}$ & $\begin{array}{l}\text { Bonferonni } \\
\text { p }\end{array}$ \\
\hline Bog (Early season) & Fixed-Fixed & $9(0)$ & $8(0)$ & -0.071 & 0.630 & -0.461 & 0.651 & 1.000 \\
Bog (Early season) & Weighted-Fixed & $7(3)$ & $10(4)$ & 0.730 & 2.476 & 1.215 & 0.242 & 1.000 \\
Bog (Early season) & Equiprobable-Fixed & $11(4)$ & $6(1)$ & -0.440 & 1.290 & -1.405 & 0.179 & 1.000 \\
Bog (Late season) & Fixed-Fixed & $11(0)$ & $7(0)$ & -0.090 & 0.667 & -0.538 & 0.598 & 1.000 \\
Bog (Late season) & Weighted-Fixed & $11(3)$ & $7(2)$ & -0.045 & 1.694 & -0.112 & 0.912 & 1.000 \\
Bog (Late season) & Equiprobable-Fixed & $10(1)$ & $8(0)$ & -0.402 & 1.139 & -1.496 & 0.153 & 1.000 \\
Forest (Early season) & Fixed-Fixed & $10(0)$ & $10(0)$ & 0.079 & 0.711 & 0.494 & 0.627 & 1.000 \\
Forest (Early season) & Weighted-Fixed & $11(4)$ & $9(1)$ & -0.397 & 2.183 & -0.813 & 0.426 & 1.000 \\
Forest (Early season) & Equiprobable-Fixed & $12(2)$ & $8(0)$ & -0.262 & 1.150 & -1.020 & 0.320 & 1.000 \\
Forest (Late season) & Fixed-Fixed & $13(0)$ & $7(0)$ & -0.300 & 0.554 & -2.358 & 0.030 & 0.597 \\
Forest (Late season) & Weighted-Fixed & $15(6)$ & $5(0)$ & -2.125 & 2.362 & -3.817 & 0.001 & 0.028 \\
Forest (Late season) & Equiprobable-Fixed & $14(1)$ & $6(0)$ & -0.446 & 1.097 & -1.773 & 0.093 & 1.000 \\
\hline & & & & & & & &
\end{tabular}

form draw of species, whereas forest ant assemblages were slightly aggregated, with some adjacent species being very similar in body size and others being very dissimilar (large $\sigma_{\mathrm{sl}}^{2}$; Fig. 3).

At the local scale, bog assemblages showed a consistent trend towards even spacing: in most bogs, the observed variance in body size ratios was unusually small, although only the pattern for the simple uniform model was significant after a Bonferonni correction (Table 2; Fig. 1). In contrast, forest assemblages showed a tendency toward random or aggregated body size patterns, although none of the patterns were significant after the Bonferonni correction (Table 2).

\section{Generic diversity}

For ants of bogs, local communities consistently supported more genera (i.e. reduced species/genus ratio) than expected by chance (Table 3), which could contribute to an even spacing of body sizes. For example, the four co-existing species in Clayton Bog represented 4 different genera (Dolichoderus pustulatus, Myrmica lobifrons, Formica subserecia, Tapinoma sessile), whereas the expected number of genera in a randomly assembled community of 4 bog species was only 3.4 . This difference is not statistically significant. However, in 16 of 22 bog assemblages, the observed number of genera exceeded the number expected by random colonization. In contrast, there was no tendency for congeneric co-existence to be limited in forest assemblages (generic diversity greater than expected in only 10 of 22 assemblages.

\section{Discussion}

Although most assembly rules were first derived for insular populations of vertebrates (Gotelli 1999), we found these same rules were useful for predicting patterns in continental ant assemblages of New England. We found some support for the notion that co-occurrence of similar species may be less than expected by chance and that co-existing species exhibit regular spacing of body sizes. However, our results did depend on the spatial scale of the analysis (Levin 1992), and co-occurrence patterns were distinctly different for bog and forest ant species, despite the proximity of these habitats and the presence of many shared species (Table 4). The relatively harsh physical conditions in bogs (high acidity, low oxygen, and water-saturated substrate) may act as a strong habitat filter (Keddy and Weiher 1999), restricting the pool of potential colonists and therefore altering co-occurrence patterns. Although the results were somewhat sensitive to the type of null model used, consistent results emerged for null models that were biologically realistic and appropriate for the spatial scale of the study.

At the regional scale, species co-occurrence was nonrandom only for forest ant communities. The two null models that fixed species number per site gave consistent results: species co-occurred less than was expected. However, this pattern cannot be unambiguously attributed to competitive interactions. Forest ant species richness was highly predictable on the basis of latitude, elevation, light availability, and plant species composition (Gotelli and Ellison 2002). If some species respond differentially to such gradients (Peres-Neto et al. 2001), 




Fig. 3. Body size overlap patterns at the regional scale of analysis. The histograms give the frequencies of simulated variance in segment length $\left(\sigma_{\mathrm{sl}}^{2}\right)$, a measure of the constancy of size ratios of adjacent species (Fig. 1). For both the habitats, the null model is one in which species body sizes are distributed randomly and uniformly (log scale) between the endpoints of the largest and smallest observed species in the assemblage. Arrows indicate observed variances, with associated tail probabilities. Communities structured by interspecific competition should exhibit unusually small variances, corresponding to relatively constant body size ratios and an even spacing of species body sizes on a logarithmic scale. then subtle "habitat checkerboards" may cause species segregation that is not necessarily related to competition (Gotelli and McCabe 2002). Bog species richness was less predictable among sites (Gotelli and Ellison 2002), and there was little evidence at the regional scale of non-random co-occurrence of bog species.

At the local scale, there was no evidence for reduced co-occurrence in either habitat, no matter which null model was used. This result is similar to patterns documented for coral reef fishes, in which communities appeared to be organized by competition at large spatial scales (Anderson et al. 1981; but see Bellwood and Hughes 2001), but appeared random when analyzed at small spatial scales (Sale and Williams 1982, Sale 1984, Findley and Findley 1985). These results are surprising for ants because there is substantial evidence for competitive structure at small spatial scales (Levings and Traniello 1981, Fellers 1987, Ryti and Case 1992, Punttila et al. 1996). Our results could possibly reflect the kind of data that were used (pitfall trap catches) rather than the spatial scale per se. Pitfall catches may have revealed the spatial pattern of randomly foraging workers, whereas the spatial distribution of nest entrances (Ryti and Case 1984, Cushman et al. 1988) or the occurrence of species at food resources (Holway 1998, Albrecht and Gotelli 2000) might have reflected stronger spatial partitioning. However, most baits remained empty during the sampling period (N.J. Gotelli and A.M. Ellison, unpubl. data), suggesting that food resources were not limiting at a local scale. Moreover, pitfall traps captured over $75 \%$ of all species recorded, and we believe it is unlikely the results would have changed with other sampling methods, such as baits.

Only a few other studies have used null model analyses to investigate ant community structure. Simberloff (1983) used an equiprobable regional species pool and re-analyzed the harvester ant data of Davidson (1977); he found no evidence for the hypothesis that similar species could not co-exist unless they differed in foraging mode (group vs individual). In ant assemblages of prairie grasslands, niche overlap in bait utilization was

Table 2. Meta-analysis of effect sizes for body size overlap patterns at the local scale. Data organized as in Table 1 . Communities with constant body size ratios should frequently reject the null hypothesis in the lower tail, and the meta-analysis pattern would be an effect size significantly less than 0.0 .

\begin{tabular}{llccccrcc}
\hline Habitat & Model & $\begin{array}{l}\text { Lower } \\
\text { tail }\end{array}$ & $\begin{array}{l}\text { Upper } \\
\text { tail }\end{array}$ & $\begin{array}{l}\text { Average } \\
\text { effect size }\end{array}$ & $\begin{array}{l}\text { SD of } \\
\text { effect size }\end{array}$ & $\mathrm{t}$ & $\mathrm{p}$ & $\begin{array}{l}\text { Bonferonni } \\
\mathrm{p}\end{array}$ \\
\hline Bog & Uniform & $14(1)$ & $3(0)$ & -0.566 & 0.581 & -4.019 & 0.001 & 0.008 \\
Bog & Equiprobable & $14(2)$ & $3(0)$ & -0.364 & 0.650 & -2.309 & 0.035 & 0.277 \\
Bog & Occurrence Weights & $14(2)$ & $3(0)$ & -0.352 & 0.662 & -2.193 & 0.043 & 0.347 \\
Bog & Abundance Weights & $14(3)$ & $3(0)$ & -0.316 & 0.709 & -1.839 & 0.085 & 0.667 \\
Forest & Uniform & $10(0)$ & $12(0)$ & 0.171 & 0.725 & 1.107 & 0.281 & 1.000 \\
Forest & Equiprobable & $7(1)$ & $15(1)$ & 0.507 & 0.861 & 2.762 & 0.012 & 0.093 \\
Forest & Occurrence Weights & $7(0)$ & $15(1)$ & 0.538 & 0.881 & 2.866 & 0.009 & 0.074 \\
Forest & Abundance Weights & $7(1)$ & $15(1)$ & 0.516 & 0.871 & 2.779 & 0.011 & 0.090 \\
\hline
\end{tabular}


Table 3. Expected and observed ant generic diversity in bogs and forests. For each local assemblage $(\mathrm{n}=22)$, the expected and observed number of genera based on random draws of species from the regional source pool. Entries are the number of local assemblages for which the observed number of genera was greater than the expected number. The binomial test is for the null hypothesis that deviations above and below the expected number of general occurred with equal frequency.

\begin{tabular}{llll}
\hline Habitat & $\begin{array}{l}\text { Observed number of } \\
\text { genera }>\text { expected }\end{array}$ & $\begin{array}{l}\text { Observed number of } \\
\text { genera }<\text { expected }\end{array}$ & Binomial test \\
\hline Bog & 16 & 6 & 0.026 \\
Forest & 10 & 12 & 0.738 \\
\hline
\end{tabular}

Table 4. Summary of null model analyses of bog and forest assemblages at regional and local spatial scales.

\begin{tabular}{lllllll}
\hline & Co-occurrence & & & Body size overlap & \\
\cline { 2 - 3 } \cline { 5 - 6 } & Bog & Forest & & Bog & Forest \\
\hline $\begin{array}{llllll}\text { Regional scale } \\
\text { Local scale }\end{array}$ & $\begin{array}{lllll}\text { Random or weakly aggregated } \\
\text { Random }\end{array}$ & $\begin{array}{l}\text { Segregated } \\
\text { Random }\end{array}$ & & & $\begin{array}{l}\text { Random } \\
\text { Weakly segregated }\end{array}$ & $\begin{array}{l}\text { Weakly aggregated } \\
\text { Random }\end{array}$ \\
\hline
\end{tabular}

less than expected by chance, although the patterns varied seasonally and diurnally (Albrecht and Gotelli 2000). In the eastern United States, regional co-occurrence of both forest and open field ant assemblages was less than predicted by the fixed-fixed null model, although this pattern broke down in the presence of the invasive red fire ant, Solenopsis invicta (Gotelli and Arnett 2000).

The best examples of reduced body size overlap have come from detailed analyses of North American desert rodents (Bowers and Brown 1982, Brown and Nicoletto 1991), Middle Eastern mammalian carnivores (Dayan et al. 1989, 1990, 1992), Caribbean Anolis lizards (Haefner 1988, Losos 1990, 1995), Galapagos Island finches (Schluter and Grant 1984, Schluter et al. 1985), and North American stickleback fishes (Schluter and McPhail 1992).

Fewer examples exist for invertebrates assemblages, which are often described as unsaturated with many empty niches (Lawton and Strong 1981, Rohde 1991; but see Kuris and Lafferty 1994). However, regular spacing of body size and morphology has been detected in North American freshwater molluscs (Dillon 1981), European ground beetles (Brandl and Topp 1985), and British hoverflies (Gilbert et al. 1985). In the latter two examples, regular spacing was detected only for assemblages in undisturbed habitats. Other statistical tests of body size ratios in invertebrate assemblages have revealed patterns that were random or not consistently segregated (Simberloff and Boecklen 1981, Juliano and Lawton 1990, Foote 1991, Pearson and Juliano 1991).

How might constant body size ratios in ant assemblages arise in ecological time? A long-standing hypothesis in the biogeographic literature (Elton 1946, Williams 1947, Järvinen 1982) is that species/genus ratios might be reduced in competitively structured communities because there is a limit to how many congeneric species can co-exist locally. Because body sizes differ greatly between New England ant genera, a pattern of reduced species/ genus ratios in local communities might itself contribute to the pattern of constant body size ratios. Rarefaction analysis supports this hypothesis (Table 3). Enemy-free space (Jeffries and Lawton 1984) is another explanation for even body size spacing, but there is little evidence that mid-latitude ant communities are strongly controlled by predation or parasitism. Our findings are consistent with other evidence that ant body size has important consequences for resource utilization and species interactions (Davidson 1978, Cole 1983, Retana and Cerdá 1995, Kaspari and Weiser 1999, McGlynn 1999). Keddy and Weiher (1999) point out that very few studies of community assembly explicitly state the assembly rules that were derived. For ants of New England forests and bogs two assembly rules emerge from our analyses: 1) at the regional scale, forest ant species co-occurred less frequently than expected by chance. 2) at the local scale, body size ratios of co-existing species in bogs tended towards constancy, accompanied by greater generic diversity than expected.

Acknowledgements - We thank Stefan Cover and André Francoeur for extensive help and advice with ant species identification. We thank our hard-working field crews in Vermont (Heidi Albright, Yvette Luyten, Matt Toomey), Massachusetts and Connecticut (Rebecca Emerson, Kirsten McKnight, and Samantha Williams) for ant sampling. The manuscript benefited from discussion and comments by Brian Fisher, Ulrich Mueller, and the instructors and students of the "The Ant Course" (Summer 2001).This work was supported by grants DEB 98-05722 and DEB 98-08504 from the US NSF, and contract MAHERSW99-17 from the Massachusetts Natural Heritage and Endangered Species Program. Null model software development supported by NSF grants 97-25930 and DEB 01-07403.

\section{References}

Albrecht, M. and Gotelli, N. J. 2000. Spatial and temporal niche partitioning in grassland ants. - Oecologia 126: $134-141$

Andersen, A. N. 1992. Regulation of "momentary" diversity by dominant species in exceptionally rich ant communities of the seasonal tropics. - Am. Nat. 140: 401-420. 
Andersen, A. N. 1997. Functional groups and patterns of organization in North American ant communities: a comparison with Australia. - J. Biogeogr. 24: 433-460.

Andersen, A. N., Blum, M. S. and Jones, T. H. 1991. Venom alkaloids in Monomorium "rothsteini" Forel repel other ants: is this the secret to success by Monomorium in Australian ant communities? - Oecologia 88: 157-160.

Anderson, G. R. V., Ehrlich, A. H., Ehrlich, P. R. et al. 1981 The community structure of coral reef fishes. - Am. Nat. 117: 476-495.

Bellwood, D. R. and Hughes, T. P. 2001. Regional-scale assembly rules and biodiversity of coral reefs. - Science 292: $1532-1534$.

Bowers, M. A. and Brown, J. H. 1982. Body size and coexistence in desert rodents: chance or community structure? Ecology 63: 391-400.

Brandl, R. and Topp, W. 1985. Size structure of Pterostichus spp. (Carabidae): aspects of competition. - Oikos 44 234-238.

Brown, J. H. and Nicoletto, P. F. 1991. Spatial scaling of species composition: body masses of North American land mammals. - Am. Nat. 138: 1478-1512.

Brown Jr., W. L. 1953. Revisionary studies in the ant tribe Dacetini. - Am. Midl. Nat. 50: 1-137.

Brown, W. L. and Wilson, E. O. 1956. Character displacement. - Syst. Zool. 5: 49-64.

Cerdá, X., Retana, J. and Manzaneda, A. 1998. The role of competition by dominants and temperature in the foraging of subordinate species in mediterranean ant communities. - Oecologia 117: 404-412.

Cole, B. J. 1983. Assembly of mangrove ant communities: patterns of geographical distribution. - J. Anim. Ecol. 52: $339-347$.

Connor, E. F. and Simberloff, D. 1979. The assembly of species communities: chance or competition? - Ecology 60 : $1132-1140$

Cornell, H. V. 1999. Unsaturation and regional influences on species richness in ecological communities: a review of the evidence. - Ecoscience 6: 303-315.

Cushman, J. H., Martinsen, G. D. and Mazeroll, A. I. 1988 Density- and size-dependent spacing of ant nests: evidence for intraspecific competition. - Oecologia 77: 522-525.

Davidson, D. W. 1977. Species diversity and community organization in desert seed-eating ants. - Ecology 58: 711-724.

Davidson, D. W. 1978. Size variability in the worker caste of a social insect (Veromessor pergandei Mayr) as a function of the competitive environment. - Am. Nat. 112: 523-532.

Dayan, T., Simberloff, D., Tchernov, E. and Yom-Tov, Y. 1990. Feline canines: community-wide character displacement among the small cats of Israel. - Am. Nat. 136 $39-60$.

Dayan, T., Simberloff, D., Tchernov, E. and Yom-Tov, Y. 1992. Canine carnassials: character displacement in the wolves, jackals and foxes of Israel. - Biol. J. Lin. Soc. 45 315-331.

Dayan, T., Tchernov, E., Yom-Tov, Y. and Simberloff, D 1989. Ecological character displacement in Saharo-Arabian Vulpes: outfoxing Bergmann's rule. - Oikos 58: 263-272.

Diamond, J. M. 1975. Assembly of species communities. - In Cody, M. L. and Diamond, J. M. (eds), Ecology and evolution of communities. Harvard Univ. Press, pp. 342 444.

Dillon, R. T. J. 1981. Patterns in the morphology and distribution of gastropods in Oneida Lake, New York, detected using computer-generated null hypotheses. - Am. Nat 118: $83-101$.

Drake, J. A. 1990. Communities as assembled structures: do rules govern pattern? - Trends Ecol. Evol. 5: 159-164.

Elton, C. 1946. Competition and the structure of ecological communities. - J. Anim. Ecol. 15: 54-68.

Fellers, J. H. 1987. Interference and exploitation in a guild of woodland ants. - Ecology 68: 1466-1478.
Findley, J. S. and Findley., M. T. 1985. A search for pattern in butterfly fish communities. - Am. Nat. 126: 800-816.

Foote, M. 1991. Morphological and taxonomic diversity in a clade's history: the blastoid record and stochastic simulations. - Contributions. - Ann Arbor Mus. Paleontol. 28: $101-140$.

Gilbert, F. S., Harding, E. F., Line, J. M. and Perry, H. 1985. Morphological approaches to community structure in hoverflies (Diptera, Syrphidae). - Proc. Royal Soc. Lond. B 224: $115-130$.

Gotelli, N. J. 1999. How do communities come together? Science 286: 1684-1685.

Gotelli, N. J. 2000. Null model analysis of species co-occurrence patterns. - Ecology 81: 2606-2621.

Gotelli, N. J. and Arnett, A. E. 2000. Biogeographic effects of red fire ant invasion. - Ecol. Lett. 3: 257-261.

Gotelli, N. J. and Colwell, R. K. 2001. Quantifying biodiversity: Procedures and pitfalls in the measurement and comparison of species richness. - Ecol. Lett. 4: 379-391.

Gotelli, N. J. and Ellison, A. M. 2002. Biogeography at a regional scale: determinants of ant species density in New England bogs and forests. - Ecology 83: 1604-1609.

Gotelli, N. J. and Entsminger, G. L. 2001a. EcoSim: null models software for ecology. Version 6.0. - Acquired Intelligence Inc. \& Kesey-Bear. http:/ homepages.together.net/ gentsmin/ecosim.htm.

Gotelli, N. J. and Entsminger, G. L. 2001b. Swap and fill algorithms in null model analysis: rethinking the Knight's Tour. - Oecologia 129: 281-291.

Gotelli, N. J. and Graves, G. R. 1996. Null models in ecology. - Smithsonian Inst. Press.

Gotelli, N. J. and McCabe, D. J. 2002. Species co-occurrence: a meta-analysis of J.M. Diamond's assembly rules model. - Ecology 83: 2091-2096.

Grant, P. R. 1972. Convergent and divergent character displacement. - Biol. J. Lin. Soc. 4: 39-68.

Haefner, J. W. 1988. Assembly rules for Greater Antillean Anolis lizards. Competition and random models compared. - Oecologia 74: 551-565.

Haukisalmi, V. and Henttonen, H. 1998. Analyzing interspecific associations in parasites: alternative methods and effects of sampling heterogeneity. - Oecologia 116: 565-574

Herbers, J. M. 1989. Community structure in north temperate ants: temporal and spatial variation. - Oecologia 81: 201211.

Hölldobler, B. and Wilson, E. O. 1990. The ants. - Belknap Press.

Holway, D. A. 1998. Effect of Argentine ant invasions on ground-dwelling arthropods in northern California riparian woodlands. - Oecologia 116: 252-258.

Hurlbert, S. H. 1971. The nonconcept of species diversity: a critique and alternative parameters. - Ecology 52: $577-$ 585 .

Hutchinson, G. E. 1959. Homage to Santa Rosalia or why are there so many kinds of animals? - Am. Nat. 93: 145-159.

Järvinen, O. 1982. Species-to-genus ratios in biogeography: a historical note. - J. Biogeogr. 9: 363-370.

Jeffries, M. J. and Lawton, J. H. 1984. Enemy free space and the structure of ecological communities. - Biol. J. Lin. Soc. 23: $269-286$.

Juliano, S. A. and Lawton, J. H. 1990. The relationship between competition and morphology. I. Morphological patterns among co-occurring dytiscid beetles. - J. Anim. Ecol. 59: 403-419.

Kaspari, M. and Weiser, M. D. 1999. The size-grain hypothesis and interspecific scaling in ants. - Funct. Ecol. 13: $530-538$.

Keddy, P. and Weiher, E. 1999. The scope and goals of research on assembly rules. - In: Weiher, E. and Keddy, P. (eds), Ecological assembly rules: perspectives, advances, retreats. Cambridge Univ. Press, pp. 1-20.

Kuris, A. M. and Lafferty, K. D. 1994. Community structure: larval trematodes in snail hosts. - Annu. Rev. Ecol. Sys. 25: $189-217$ 
Lawton, J. H. and Strong Jr., D. R. 1981. Community patterns and competition in folivorous insects. - Am. Nat 118: $317-338$

Levin, S. A. 1992. The problem of pattern and scale in ecology. - Ecology 73: 1943-1967.

Levings, S. C. and Traniello, J. F. A. 1981. Territoriality, nest dispersion, and community structure in ants. - Psyche 88: $265-319$.

Longino, J. T. 1997. Ants of Costa Rica: Pheidole.. http:// www.evergreen.edu/user/serv

-r...arthropod/GENERA/Pheidole/genus.html.

Losos, J. B. 1990. A phylogenetic analysis of character displacement in Caribbean Anolis lizards. - Evolution 44: 558-569.

Losos, J. B. 1995. Community evolution in Greater Antillean Anolis lizards: Phylogenetic patterns and experimental tests. - Philos. Trans. R. Soc. Lond. Ser. B - Biol. Sci. 349: 69-75.

MacArthur, R. H. and Levins, R. 1967. The limiting similarity, convergence, and divergence of coexisting species. Am. Nat. 101: 377-385.

Manly, B. F. J. 1991. Randomization and Monte Carlo methods in biology. - Chapman and Hall.

Manly, B. F. J. 1995. A note on the analysis of species co-occurrences. - Ecology 76: 1109-1115.

McGlynn, T. P. 1999. Non-native ants are smaller than related native ants. - Am. Nat. 154: 690-699.

Morrison, L. W. 1996. Community organization in a recently assembled fauna: the case of Polynesian ants. - Oecologia 107: $243-256$

Pearson, D. L. and Juliano, S.A. 1991. Mandible length ratios as a mechanism for co-occurrence: evidence from a worldwide comparison of tiger beetle assemblages (Cicindelidae). - Oikos 61: 223-233.

Peres-Neto, P. R., Olden, J. D. and Jackson, D. A. 2001. Environmentally constrained null models: site suitability as occupancy criterion. - Oikos 93: 110-120.

Pielou, D. P. and Pielou, E. C. 1968. Association among species of infrequent occurrence: the insect and spider fauna of Polyporus betulinus (Bulliard) Fries. - J. Theor. Biol. 21: 202-216.

Poole, R. W. and Rathcke, B. J. 1979. Regularity, randomness, and aggregation in flowering phenologies. - Science 203: 470-471.

Porter, S. D. and Savignano, D.A. 1990. Invasion of polygyne fire ants decimates native ants and disrupts arthropod community. - Ecology 71: 2095-2106.

Punttila, P., Haila, Y. and Tukia, H. 1996. Ant communities in taiga clearcuts: habitat effects and species interactions. Ecography 19: 16-28.

Retana, J. and Cerdá, X. 1995. Agonistic relationships among sympatric Mediterranean ant species (Hymenoptera: Formicidae). - J. Insect Behav. 8: 365-380.

Rohde, K. 1991. Intra- and interspecific interactions in low density populations in resource-rich habitats. - Oikos 60: $91-104$.
Ryti, R. T. and Case, T. J. 1984. Spatial arrangement and diet overlap between colonies of desert ants. - Oecologia 62: $401-404$.

Ryti, R. T. and Case, T. J. 1992. The role of neighborhood competition in the spacing and diversity of ant communities. - Am. Nat. 139: 355-374.

Sale, P. F. 1984. The structure of communities of fish on coral reefs and the merit of a hypothesis-testing, manipulative approach to ecology. - In: Strong Jr., D. R., Simberloff, D., Abele, L. G. and Thistle, A. B. (eds), Ecological communities: conceptual issues and the evidence. Princeton Univ. Press, pp. 478-490.

Sale, P. F. and Williams, D. M. 1982. Community structure of coral reef fishes: are the patterns more than those expected by chance? - Am. Nat. 120: 121-127.

Sanderson, J. G., Moulton, M. P. and Selfridge, R.G. 1998. Null matrices and the analysis of species co-occurrences. Oecologia 116: 275-283.

Savolainen, R and Vepsäläinen, K. 1989. Niche differentiation of ant species within territories of the wood ant Formica polyctena. - Oikos 56: 3-16.

Schluter, D. and Grant, P. R. 1984. Determinants of morphological patterns in communities of Darwin's finches. - Am. Nat. 123: $175-196$.

Schluter, D. and McPhail, J. D. 1992. Ecological character displacement and speciation in sticklebacks. - Am. Nat. 140: $85-108$

Schluter, D., Price, T. D. and Grant, P. R. 1985. Ecological character displacement in Darwin's finches. - Science 227 . 1056- 1059

Schoener, T. W. 1974. Resource partitioning in ecological communities. - Science 185: 27-39.

Simberloff, D. 1970. Taxonomic diversity of island biotas. Evolution 24: 23-47.

Simberloff, D. 1983. Sizes of coexisting species. - In: Futuyma, D. J. and Slatkin, M. (eds), Coevolution. Sinauer Associates, pp. 404-430.

Simberloff, D. and Boecklen, W. 1981. Santa Rosalia reconsidered: size ratios and competition. - Evolution 35: 12061228

Simberloff, D. and Connor, E. F. 1981. Missing species combinations. - Am. Nat. 118: 215-239.

Stone, L. and Roberts, A. 1990. The checkerboard score and species distributions. - Oecologia 85: 74-79.

Weiher, E. and Keddy, P. (eds.) 1999. Ecological assembly rules: perspectives, advances, retreats. - Cambridge University Press.

Weseloh, R. M. 1995. Forest characteristics associated with abundance of foraging ants (Hymenoptera: Formicidae) in Connecticut. - Env. Ent. 24: 1453-1457.

Wiens, J. A. 1982. On size ratios and sequences in ecological communities: Are there no rules? - Ann. Zool. Fen. 19: 297-308.

Williams, C. B. 1947. The generic relations of species in small ecological communities. - J. Anim. Ecol. 16: 11-18.

Wilson, J. B. 1999. Assembly rules in plant communities. - In: Weiher, E. and Keddy, P. (eds), Ecological assembly rules: perspectives, advances, retreats. Cambridge Univ. Press, pp. $130-164$ 